\title{
Sustaining Mak Yong - Main Puteri in Raman: A Discussion of its Existence in Cultural Evolutionary Thread
}

\author{
Syafiq Faliq Bin Alfan \\ Graduate School of Integrated Arts and Science, Hiroshima University, Japan \\ e-mail: narutosefa@gmail.com
}

Published online: 30 November 2020

Cite this article (APA): Alfan, S. F. (2020). Sustaining Mak Yong - Main Puteri in Raman: A discussion of its existence in cultural evolutionary thread. JuraiSembah, 1(2), 1-13. https://doi.org/10.37134/juraisembah.vol1.2.1.2020

\begin{abstract}
Mak Yong, a traditional Malay dance-theatre recognised by UNESCO as one of the intangible cultural heritage of Malaysia has indeed seen its progress since its revival in the 1970s by some of its prominent artists such as Khatijah Awang of the Sri Temenggung troupe fame. Sadly, although Mak Yong belongs to the region of Kelantan-Pattani of the Malay Peninsula, the art form has seen its greater decline in its southern Thailand counterpart. This could be as a result of the political climate aside from the inclination of the local towards Sunni Islamic values that forbid some of its ritualistic elements. This is apparent especially in the neighbouring state of Kelantan where Mak Yong has already been banned to be performed in public since the early 1990s unless it adheres to the Syariah law. However, in the context of the forms' existence in Pattani, despite its resilience towards the test of time, it has not gained as much attention compared to the Kelantan counterpart. Most extensive case studies in the past were based on the Kelantanese group (Sheppard, 1974; Yousof, 1976 \& 1992; Nasuruddin, 1995). To extend our understanding of the study of Mak Yong of the Malay world, this paper aims to discuss the forms existence in Southern Thailand, particularly in the district of Raman, Yala Province. Special focus on its discussion will centre around the question of sustaining the tradition in the region through the relationship with Main Puteri, another ritualistic dance-theatre closely related to Mak Yong. Through the epistemological approach of Cultural Evolution, this paper intends to preliminarily explore the importance of this relationship in the bigger picture of Mak Yong as part of the cultural evolution in the Malay world. By identifying its natural phenomena, it is hoped that more exploration can be done in the future on the realm of Southeast Asian traditional performing arts.
\end{abstract}

Keywords: cultural evolution, dance theatre, Mak Yong, Pattani, performing arts, traditional

\section{Introduction}

In the past, studies conducted on Mak Yong and its community was heavily concentrated in Kelantan, the east coast state of Malaysia. Through the early works by notable scholars such as Mubin Sheppard (1972), it sparked the interest of other scholars such as Ghulam-Sarwar and Ghouse Nasuruddin to follow suit on the subject and explore its discourses, leading to the first inclusion of the art in the academic curricular of traditional performing arts through the Cultural Centre (Pusat Seni) of Universiti Sains Malaysia (USM) in the 1970s. Consequently, after several decades, UNESCO finally recognized it as an intangible cultural heritage of humanity in 2005. As of now, the art form is no longer alienated from the minds of the public particularly in the education sector where it has also become one of the important academic curriculum in various higher education institutions such as Akademi Seni Budaya dan Warisan Kebangsaan (ASWARA), Universiti Teknologi Mara (UiTM), University of Malaya (UM) and Sultan Idris Education University (UPSI). 


\section{Problem Statement}

Unfortunately, due to the political climate of the southern region in Thailand, Mak Yong is unable to receive such recognition at the national and consequently international level. As a result, its development was then hindered which slowly led to a greater decline among its community. The rise of Pattani's Sunni Islamic values in the consciousness of the southern Thai Malay community also complicates the interaction between the Mak Yong community and the general public around them. Islam forbids ritualistic practices as it implies the spiritual dependency on another than the one true God, Allah. This is also reflected in the neighbouring state of Kelantan, through the banning of the art form since more than 20 years ago. The recent progress (Abdullah, 2019) shows that due to its importance in gaining attraction from local tourism, the state government of Kelantan has granted permission for it to be performed without any ritualistic elements and if it adheres to the Syariah Law such as the cover of Aurah especially for women who perform and the segregation of male and female audience.

Fortunately, despite the local ban and restrictions made in Kelantan, the art form has flourished in other parts of Malaysia especially in the capital state of Kuala Lumpur, since the ban was not implemented. Over the years of public and international interest, recent efforts have been made to gather the artists and researchers alike in a festival of Mak Yong that was held in The Mak Yong Spiritual Dance Heritage Conference in 2011 (Mohamad, 2012). The importance of this conference was significant towards the appreciation and understanding of the art that has transcended beyond the boundaries of nations in Southeast Asia. Among the groups that performed at the conference besides Malaysia were from Riau Island, Indonesia and Pattani, Thailand.

\section{Research Questions and Objectives}

What has become of the groups from Southern Thailand since then? This is one of the questions that drove this study as the narrative of Mak Yong in Thailand is rarely heard of in regional studies. For this study, one particular community in the Raman district of Yala Province, Thailand was chosen as the fieldwork location. A focal person of this study, Saman Dosormi is the key figure of this community that helps to focus and manage the group. He even curated his own house as a cultural hub called 'Kemeng Folk Museum Chalermraja Cultural Center' for any activities not just restricted to Mak Yong but other local traditional Malay culture and practices as well such as Wayang Kulit, Menora and Silat.

Through our investigation, we found out that despite the popularity decline of Mak Yong over the years in the region as compared to fifty or sixty years ago, the form still found its niche among the Malay community of the southern Thai, particularly of those around the east coast area. Prior to the interview and fieldwork, the group managed to perform a few nights before at the Prince of Songkhla University, Pattani Campus during its cultural week activities. Despite the challenges, what are the reasons behind its sustaining presence in the local community? This question too will be explored in our subsequent discussions with a particular interest towards Cultural Evolution epistemological view of the issue.

Another interesting observation obtained through the interviews in this study is the connection between Mak Yong and Main Puteri/Teri in the question of the community's sustainability and livelihood. Main Puteri is often closely associated with Mak Yong although this Malay proto-theatre is intended for spiritual healing purposes as compared to a Mak Yong performance that focuses more on the entertaining aspect. However, it is worth mentioning that these two traditional performing arts share the same philosophy, tradition, cosmology and epistemological view despite having different performance structures. Throughout the study, we will also find out other relatable traditions that could share similar traits such as Bageh in order to understand the cultural evolutionary thread better.

\section{Methodology}

\section{Data and fieldwork process}

Through Saman Dosormi's network, a total of six artists within the community in Raman was interviewed to obtain valuable information on the livelihood of the community in the area. The information from the interviews was then extracted and analyzed with some cross-references made to the previous extensive research on the art. Among the information vital to this study are to look at the oral history of senior Mak 
Yong artists in order to gather new information regarding how the performance was conducted in the past, the transfer of knowledge from their predecessors, travel patterns, economic background and main differences between the Pattani and Kelantanese Mak Yong without disregarding Riau Mak Yong in the comparison. Using these initial data, we found that there seems to be a connection between Mak Yong and Main Puteri in terms of matter pertaining to inheritance and its sustenance as part of the cultural evolutionary process. However, it is important to note that this paper will only serve as a preliminary study on Pattani's Mak Yong and to differentiate it with its Kelantanese and Riau counterpart despite having the same historical foundation in the past. Falling under different political identity, each community developed its own unique style of approaching certain aspects of the performance, despite having very similar roots to which we will visit shortly.

\section{Cultural evolution, the epoxy for data comparison}

In our recent understanding on Mak Yong, we realized the form has reached the trans-national boundary and spread across Indonesia, Malaysia and Thailand while still confined within the larger Malay world in Southeast Asia. This triggers the question on the process involved that would affect the progression of this form across different localities. Despite having different forms of Mak Yong in different regions across Southeast Asia, the art is considered to have originated from the Pattani - Kelantan region by its artists and communities. While the major ethnic group between the Thailand - Kelantan state border is still considered within the same subgroup of local east coast Malay due to their common history prior to Anglo - Siamese Treaty 1909, the same could not be said for the Riau Islands, located $800 \mathrm{~km}$ away and exist within the Indonesian territory today. This prompts us to look at different forms of Mak Yong using a theoretical framework that would connect and explain the natural cause affecting its cultural progression in different localities, which in this case, around $800 \mathrm{~km}$ apart. However, due to the focus of this paper, which is to look at Raman's Mak Yong community, we will visit these different forms of Mak Yong in relation to Raman's community and their perception towards them as we try to understand the bigger picture. By doing so, we can also understand the social interactions between different groups and how it further contributes to the cultural evolution of Mak Yong in the Malay world.

While studies of the art in the past utilized ethnographic or anthropological approach (Yousof, 1976; Sheppard, 1972; Cuisinier, 1936; Pudentia, 2010; Hardwick, 2009) in understanding the structure, conventions and its folk cosmology, our concern in this paper is to use a more pragmatic approach in explaining the natural phenomena that occurs within or between communities across the region. Despite rigorous efforts in understanding Mak Yong over the years, some issues remain unclear surrounding its cultural progression especially on the distinct variation of features in different localities such as in Sumatera and Riau. Due to the nature of the art that relies heavily on oral transmission, some of the important knowledge that would benefit our understanding is most likely lost after several generations, thus leaving us to question on some of its missing links with the earlier official records. Among the many theoretical frameworks available, our best option is to utilize the Darwinian Cultural Evolution to address issues pertaining to cultural progression observed in this paper. Due to the phenomena of interest that not only occurred around the Kelantan - Pattani region but also around the Riau Island as well, we need to approach some of the issues by comparing Mak Yong data gained within these regions. If we could consider that every Mak Yong that existed within these regions are somehow related to one another through their earlier ancestral form, then past studies focusing on each form can be correlated and compared to one another rather than treating them as separate cultural phenomena. This can also be applied to traditional performing arts that are related to Mak Yong such as Main Puteri and Bageh. Without disregarding past studies and approaches towards the study of the art, the Darwinian theory applied in this paper will be used to enrich our understanding. This utilization also serves to encourage more interdisciplinary and integrated approaches to explain the socio-cultural progression of the community in future studies.

\section{The respondents}

The six respondents of this study besides Saman Dosormi are Mok Noh (Minah Saman), Che Din (Dain Senik), Mok Moh (Nawar Samad/ Selamoh), Che Teh (Lateh Senik), Mok Timoh (Timoh Senik) and Wori (Dahari Emong). Besides Wori - who is the new generation of Mak Yong performers, the rest are the seniors in this community between the ages of $60-80$ years old. Che Teh and Che Din are siblings while Mok Moh 
is Che Din's wife and Mok Timoh is married to Che Teh. Mok Noh is currently the leader of the three Mak Yong groups left in the area, while the other two are led by Kak We and Che Jenab. In this community, Saman Dosormi is the key member of this community in bridging the old generation with the current one, as he is not only knowledgeable in the local Malay customs and traditions but also able to speak and read Thai language due to his educational background unlike most of the senior members of the community. Through his network, the group was able to perform not only at institutions of higher learning such as in Prince of Songkhla University but also at official government-related events. Without such connections, the community might resort to shamanistic healing rituals of Main Puteri as a means to earn a living although it could not be said that all members of the community have the knowledge to perform it. Che Din explained that while he desires to do shamanistic healing of bomoh, he could not perform as a Peran in Main Puteri as it requires a different set of skills. Mok Noh too expressed the same concern towards this approach as she only inherited the knowledge of playing Pak Yong and Mak Yong's conventions, not Main Puteri.

Usually, the key members of the group will discuss the arrangements prior to the event on whom should be included in their next performance. Currently, in the case of Mok Noh, she will first discuss with Saman Dosormi should he receive offers of a slot before reaching out to the rest of the members on their availability. It can be said that a particular Mak Yong group will not have its own permanent members, rather, it is a loose collective of members within a small community in order to achieve its objective of artistic pursuits. In the past, members of this Mak Yong community have participated in performances either as one or collaborated with other Mak Yong artists and communities from other areas. There are no obligations to each of them in performing only with the group. Most of the time, the network is shared through family connections. Due to the nature of their activity, each member of the community may have separate experiences and influences outside of Mak Yong and might bring these new influences or improvement in some aspects of Mak Yong. This fact coincides with the findings by A. S. Hardy on Mak Yong groups in Kelantan that had learned of some aspects of commercial performance management through their experience with Bangsawan, another form of local traditional theatre (Shafii, 2017). In the case of Che Teh, he was also once involved in a local Bangsawan production, whereby the show was adapted from a popular film played in the cinema at that time. Another example is Wori, where he had once travelled to Japan for his Dikir Barat performance. Despite these individual differences, the community sticks true to its traditional roots when performing Mak Yong and adhere to its rules, conventions and traditions.

\section{Result}

\section{Revisiting Main Puteri - Mak Yong}

Before we begin to understand the connection between Mak Yong and Main Puteri, it is best for us to revisit past research in regards to both performing arts and its connection in order to comprehensively understand the context of its existence and social function. Despite Mak Yong being officially recorded over 100 years, deeper contextualized research on Mak Yong - Main Puteri is fairly recent. Ghulam - Sarwar regards Main Puteri as a type of Malay Proto-Theatre, a term he coined for Malay traditional theatre that are "[...] elementary ones which come from two principal sources: story-telling and ritual activity" (Yousof, 2014).

Out of all the Malay Proto - Theatre, he regarded Main Puteri as the most important. Other related forms of healing performances closely tied with Main Puteri is Bageh which could be a possible earlier form of Main Puteri as it shares similar features and belief system (Yousof, 2004), which we will visit later in this paper. This is also agreed by Aboo Backer et al. (2017) in their findings as well. Despite Main Puteri's unknown origin, the healing ritual shows connection with Cambodian, Thai and Malaysian aboriginal healing rituals (Yousof, 2004). A typical ensemble consists of Tok Teri, Tok Minduk and a group of musicians that will accompany the ritual. The basic idea of this healing ritual is firstly, diagnostic, which will be done by a shaman, or bomoh where he will identify the type of sickness or angin through the process called isihangin. In this process, without the musical accompaniment, the bomoh will make narration of stories, singing or simple chanting. If the process proves insufficient to heal the patient, then Main Puteri will then be suggested to the patient and family. In Main Puteri, a more elaborate circumstance will commence as the family of the patient (called tuan kerja) is required to provide a proper panggung or performance space, preparing many items for the kenduri or feast and other required paraphernalia. This depends on a case-by-case basis, as the simplest circumstance only requires limited spaces in the home of the patient. While the ritual healing of Main Puteri has its basic structure, steps in achieving the objective of treatment relies heavily upon early diagnostic on the type of illness called angin. A deep discussion on 
types of psychosomatic illness through the concept of angin were discussed by Ghulam-Sarwar Yousof (2004) in his previous writings. These categorizations of illness are important for the bomoh to take the next course of action in order to treat the patient correctly as different treatments require different preparation in terms of participant and physical preparation such as the panggung or items for offerings.

Among the many types of Main Puteri performances listed by Ghulam - Sarwar which are a) ordinary performances for healing situations, b) Main Puteri within ritual Mak Yong c) Berjamu performances of Main Puteri d) Main Puteri within Wayang Kulit Siam, our concern in this paper is to focus on the d) Main Puteri - Mak Yong performance. While the Main Puteri function is generally utilized as a healing ritual, Main Puteri - Mak Yong is intended for healing the sickness associated with angin Mak Yong. Generally, the performance structure of Main Puteri starts with buka panggung ritual or angkat kenduri, which starts after the nightly Isyak prayer for muslim. This is followed by the musical number of lagu bertabuh signaling the opening of the panggung before moving into the musical accompaniment of lagu-lagu permulaan. Tok Minduk will then sing lagu bertabik as a salutation for the past teachers of Main Puteri and recite mantras to ensure the safety of the observers and the procession from evil spirits. Tok Teri will then appear and sing the lagubergerak before going into the panggil lupa raja and penggawa segment (Shafii et al., 2017). The following stage will be of the most important in Main Puteri as Tok Teri will then diagnose the type of illness of the patient before going into trance. Shafii et al., (2017) reported that in this segment of the diagnosis called bersiuk, Tok Teri will use bertihor parched corn to determine the patient's element, whether they are wind, water, earth or fire based. Tok Teri will then move uncontrollably signaling the descend of the spirits accompanied by the music. In this session, the process could take a while as each descended spirit are interrogated by Tok Minduk in order to find which one that caused the illness of the patient. If it is identified, then Tok Minduk will either negotiate, plead, bargain or even threaten them to leave the patient's body. Offerings and sacrifices that have been placed in the bangsalor panggung will be offered to the spirit should they comply. As observed by Shafii et al. (2017), offerings includes nasi guru, jasmine flowers, perfume, betel nut leaves, banana, egg fritters, water, yellow glutinous rice, parched corn cigarette rolls and pancakes. In another report by Patricia Ann Hardwick (2009) through her dissertation, during the diagnostic process, the tranced Tok Teri, Tok Minduk will converse with different parts of the body that was represented by different spirits. These supernatural beings that guarded these seven different parts of the body will be interrogated one by one until they reported of some illness within the area of the body where they stood guard. In the case of black magic, these guardian spirits of life will report the evil spirits that have invaded or caused the illness to the patient.

In the case where angin Mak Yong is observed, it will be extended to be included in a performance of Mak Yong together with the patient acting as a major character that they are identified with, either Dewa Muda, Dewa Pechil, Gerak Petra or other characters. Usually the patient will be donning a costume and act as Pak Yong while being guided by a more experienced Pak Yong. Here, he or she will mirror the performance of their guide until the patient is emotionally released and achieving the objective of the performance. As such, the intention of the performance is different than the entertainment aspect of Mak Yong where completing the story is not a necessity, as long as the patient recovers from the illness. Selected segment of stories that are often used for healing purposes other than the popular Dewa Muda include Anak Raja Gondang and Dewa Pechil. It should be noted that despite the probable size of preparatory for the occasion, in some cases there could be a need to have a follow up for these treatments in order to strengthen the spirit of the patient to avoid them falling sick again. It is of no surprise that due to these interactions between the healer and the family of the sick, a sort of bond is created that resulted in them having a favourite bomoh (according to Ghulam - Sarwar), despite the extensive preparation needed for the occasion. In the next section, we will investigate the role of Mak Yong - Main Puteri towards the people of Raman District and how it contributes to the sustenance of Mak Yong and its community despite the decline due to the change of time.

\section{The role of Mak Yong - Main Puteri in the community of Raman district}

In this community, Mak Yong serves not only as the livelihood of its members but also as a means to connect with their spirituality and healing purposes. Despite having access to public health facilities, the locals believe that some sickness could not be treated via modern medication. In the case of Wori, he once had a fever that lasted a year when he was 10 years old. Through the introduction of spiritual healing of Main Puteri by his granduncle, the sickness was treated and ever since then, he viewed Mak Yong as a way to regenerate his spirituality, as a means to refresh one's soul. It is interesting to see that a similar case was 
experienced by Mok Timoh as well, where she was healed by Che Teh's sister, Kak We. The healing process serves not only to revitalize spirituality but also as a 'gate' to initiate new members into the community. Both Mok Timoh and Wori come from different generations but the invocation acts of Main Puteri's spiritual healing had opened the path to their inclusion in the community and much later on in Mak Yong's performances. This may be one of the few reasons why Mak Yong is still being practiced until today as it serves not only to spiritually heal the local people but also to invoke their interest and belief into the art before eventually becoming part of that network. This cycle of healing-initiation has kept the tradition alive and strong despite the friction between the pre-Islamic beliefs and the Islamic tradition being practiced by most of the southern Thai Malay community. Wori noted that the public usually shuns such sickness like 'Angin Mak Yong' and he mentioned that his household too had negative views about the sickness. Despite such criticism, he insisted on performing, as he believes in its benefits.

Other than personal experience, the clash between the two belief systems; Pre-Islamic and Sunni Islamic has occurred for some time in the consciousness of the locals via oral history. Among the oral history shared on Mak Yong is the connection to a place named Bukit Sekam in Pattani or officially called Ban Sakam in the Mayo district of Pattani Province. It is said that the place was once a bustling centre of Mak Yong activities in the past. Due to the local Raja that wanted the people of the palace to study Islam and adhere to its values, they were asked to leave the practice of the art and buried all their Mak Yong instruments and costumes at the hill after one final performance. It is said that this final performance lasted for seven days and seven nights. One day, heavy rain fell to the region and the people were afraid that it might cause a flood. In order to stop the rain, they went to Tanjung Mas (Officially: Tanyong Mat) in RaNgae district of Narathiwat Province to perform in order to avoid the sound of the percussion to be heard from afar.

Another narrative shared by Saman Dosormi is on the decline of the seven kingdoms in Pattani during the reign of King Rama II in the early nineteenth century. In the past, each territory was governed by a local ruler equipped with their own Mak Yong group. When it was slowly dissolved, each group returned to the rural villages where they kept their traditions and culture. The pattern and social progression were similar to that of the Kelantanese Mak Yong whereby the Mak Yong of Sri Temenggong village that was once supported by the palace, had lost its elite class support and slowly dissolved and dissipated into the lower class dramatically after World War II.

Our next question at hand is on the perseverance of such a belief system that has its strong hold on the society despite being shunned by some sections of the local demography. Is there a connection between the cycle of healing-initiation of Mak Yong and Main Puteri towards the resistance of strict Sunni Islamic values? Despite the decline in a number of Mak Yong practitioners and groups, the healing rituals of Main Puteri have created a strong defense against the greater rate of decline in Mak Yong practice. Saman Dosormi further explained that while the Mak Yong group in the area are left with three, Main Puteri traditions are still going strong with practitioners still playing for five to seven consecutive nights at two to four locations per month. Other locations that have strong Main Puteri tradition is Sungai Golok, located about $120 \mathrm{~km}$ from Raman and is part of the border between Thailand and Kelantan. The members of the community will usually perform at least once in a year at the Kemeng Folk Museum. The differences in the economic background are also apparent as they have their own vehicle to move around thus making it easier to manage their logistics for any performance. The Raman community, however, will need to depend on Saman Dosormi to pick every member for a performance, as they do not have the means to travel a long distance. Further investigation is needed to look at the pattern and the cycle of wealth circulation of the economy in the practice of Main Puteri in the rural areas. 


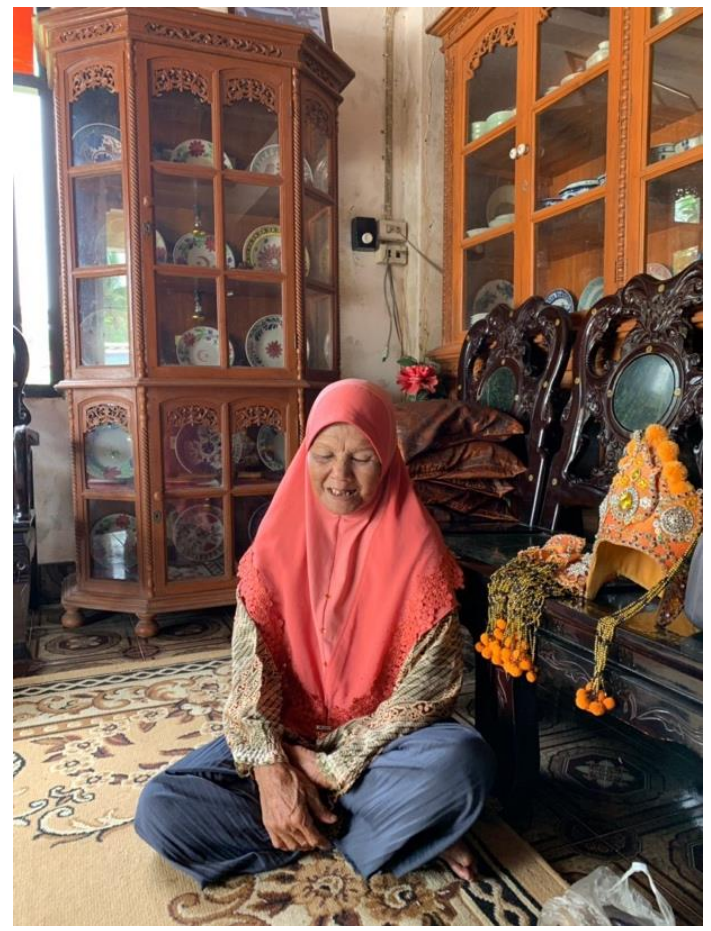

Figure 1: Mok Noh, photographed at the Kemeng Folk Museum. (Source: Author, Fieldwork, 2019)

\section{Mak Yong's artistic inheritance}

Traditionally, Mak Yong in the Raman community was inherited through the extended family system. Often, the parents or grandparents will inherit the skills from their forefathers before passing it on to their child or immediate family. Occasionally such in the case of Wori, he received the knowledge after being healed by participating in the Main Puteri healing ritual. In most cases such as Mok Noh, Che Din, Che Teh and Mok Moh, each person will undergo a few stages in the inheritance. The first and foremost is the nurture stage where most of them follow the family in every performance as they are too small to be left by themselves. Che Din recounts that most of his early childhood was spent living in a 'panggung' and that Mak Yong have since become second nature to him. While Che Din started his training with musical instruments around the age of 10 years old. Mok Noh, on the other hand, started training as a performer around the age of 13 years old before becoming the lead Pak Yong at the age of 15 years old. Despite the early nurture of the art in the family, it seems that there are no obligations for each member to only dedicate himself or herself to Mak Yong, as Che Teh also developed his interest in Bangsawan.

Comparatively, it is interesting to see that Mok Noh and Che Din forged a different path where one specializes in performing as Pak Yong while the other becoming Peran and playing musical instruments. It seems in this early observation, that gender plays a vital role in assigning a character for family members. Saman Dosormi and Che Din recalled that in the past, the role of Pak Yong was mostly played by a male lead. This could be due to the social norm at that time whereby having a female lead could invoke a negative social implication such as arousing male attraction regardless of the marital status of the said lead female. The travelling nature of Mak Yong groups in the past made it difficult for females to be in the leading role. Mok Noh stated that one of the traditions of the Mak Yong group in the past was that the group would never leave their musical instruments even after the performance has ended in spite of its location. Depending on the location of the performance stage, which could be in the middle of a paddy field or cattle shed, the performers will spend the night and sleep where they kept their instruments.

Che Din and Che Teh recalled a rare example of a female Mak Yong lead back in the day through the encounter with a performer called 'Anak Ular'. Both Che Din and Che Teh explained that this mystery figure could not be identified clearly as she wore a veil that closed her entire face except her eyes. Che Muda who was the leading man of the group at that time wanted to see her with his own eyes as she also performed in the same area but could not due to the veil that she wore. It is believed that she came from Narathiwat and may bear the name 'Mek Jah'. This describes how the female performer's appearance in 
public, intends to avoid the attraction of the male audience outside of a performance despite the entertainment aspect of this traditional theatre shown to the public.

Unfortunately, even though most senior members of the community dedicated their life to the art, it could not be sustained to the next generation within their immediate families such as their children or grandchildren. This resulted in the gradual decline of the art in the region. Further study is needed to look at the pattern of decline of interest among the senior members' next of kin. Mok Noh, Che Teh and Che Din reflected upon this loss of interest in their children and grandchildren by stating that they are the last of the senior members in the community around the area. It seems that the fate of the art lies within the effort of Saman Dosormi in inheriting the knowledge and continuing the cycle before it will be passed down to the next generation after his.

\section{Analysis and Findings}

\section{Differences between Raman and Kelantanese Mak Yong}

Generally, according to Mok Noh, there is not much of a difference between their version of Mak Yong and the Kelantanese version. Although the same could not be said about Riau's Mak Yong, as it seemed strange to Mok Noh who had observed the performance at the Mak Yong Spiritual Dance Heritage Conference in 2011. Aside from the noticeable language used in the performance that is different from the east coast dialect, the missing Rebab as an instrument in the musical ensemble is another point of deviation. In comparing the Kelantanese and Pattani Mak Yong, Che Din gives a subtle yet important explanation in the conduct of the performance, particularly in the music aspect of the performance. It seems that the Kelantanese Mak Yong adheres to the musical structure played in the performance whereas Pattani's Mak Yong has more freedom to play the music without depending too much on the aspect of time. Their approach in playing music concerns the suitability of the musical melody and the rhythm that accompanies the singers, a technique noted by Che Din as opposite to the western musical structure. Depending on the vocal range and quality of Pak Yong, the musical instruments will complement to find the perfect harmony between the two.

In the conventional way of music practiced today, it will take a composer to understand the musical notation before finding the perfect balance of harmony between players and singers. In the case of Mak Yong, through familiarity with the melody, the group must find a way to suit each other's range to find perfect harmony. Conventional music bases its performance on a documented musical notation and will try its best to follow the notation of the performance. Other subtle differences between the Kelantan and Pattani Mak Yong are the character sequence of Peran Muda and Peran Tua's appearance. In Kelantan, the Peran Tua will make the first appearance while the Pattani Mak Yong will have Peran Muda appearing first. Despite having the artistic freedom to improvise, the Kelantanese Mak Yong nevertheless have material documentation as a point of reference whereas the Pattani Mak Yong depends on the memory of the community members thus susceptible to organic change over the course of generations as in the case with Mak Yong Riau (Pudentia, 2010).

Our concern here is to see the perspectives of the Mak Yong community in a performance. Under its terms and conventions, it will lead us to understand how a variety of artistic expressions will lead to the evolution of culture under different social settings. It is interesting to make connections and compare the traditional approaches between the three regional Mak Yong styles, namely in Kelantan, Pattani and Riau, to look at how different communities branch off from its source material and evolve to suit the local context in terms of its performance. Among questions left unanswered is the prominent utilization of the mask in Riau that is credited to the Mak Yong group originating from Kelantan. Interestingly, no Mak Yong of today in Kelantan and Pattani uses a mask in the performance although historical records from the Thailand National Archive (Phongphaiboon et al., 2000) and Skeat's (1900) show otherwise. Could it be that the decision to abandon the mask in the past has a connection with the oral history told by Saman Dosormi on the act of burying Mak Yong's paraphernalia in Bukit Sekam? Further investigation is needed to verify this and fortunately, the descendants of the Mak Yong Primadonna photographed and stored in the National Archive of Thailand is said to be alive in Khok Pho by the name of Teh Wo. 


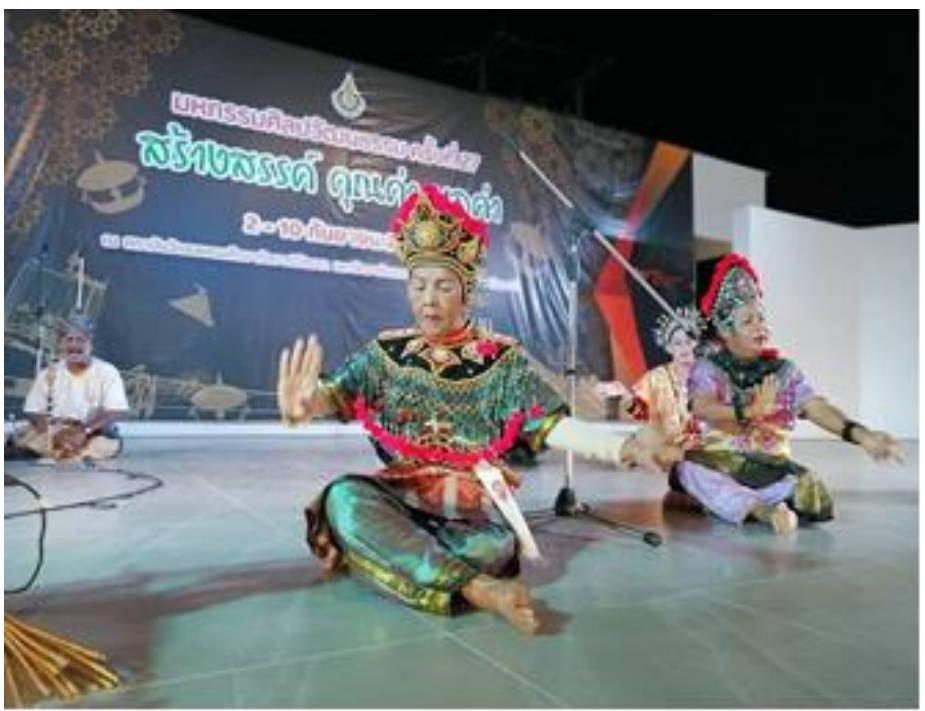

Figure 2: Mok Noh and Farok Zakaria (Source: Prince of Songkhla University)

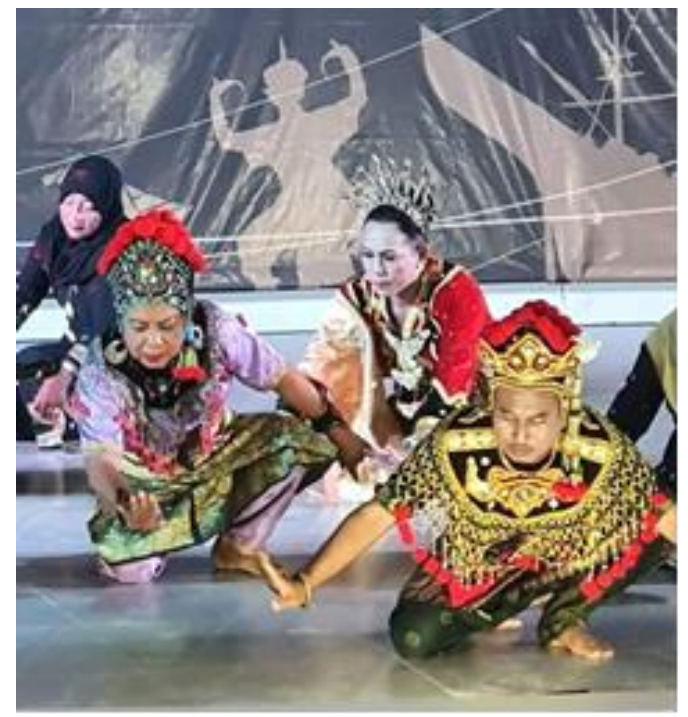

Figure 3: Farok Zakaria with Wori and Saman Dosormi (Source: Prince of Songkhla University)

\section{Discussion}

Through data gathered from this preliminary study, we now know that several interesting cultural evolution phenomena can be observed. One of those is the mode of cultural transmission among Mak Yong artists in the community. As shared by all respondents, it seems that the prevalent feature of cultural transmission in the community is through the vertical and oblique pathway; through parents or the elders. In the case of Mok Noh, Che Din and Che Teh, they inherited the skills in Mak Yong from their parents or their grandparents, whereas, in the case of Wori, he acknowledged that his interest was invoked after the healing rituals done by his granduncle's acquaintance, signaling the oblique pathway. It is also interesting to note that while the oblique and vertical mode of transmission is prevalent, none can observe for horizontal transmission. Although this is such the case, the cultural transmission of other forms of traditional performing arts also influences the learning curve of an artist as shared by Che Teh through his interest and participation in Bangsawan with his friends. If there is such a way for Lamarckian cultural evolution to play its part in the evolutionary process, it could be through the horizontal transmission among parents' or grandparents' before it can be passed down to the next generation in their lifetime. Could this be the answer to the change of mask utilization in Mak Yong's performance in Kelantan - Pattani region or the loss of 
Rebab utilization in Riau? As vertical and oblique pathways are the most apparent in the transmission, perhaps any changes (or mutation) made in the genre could most possibly come from the older generation.

Among the evidence that could support such processes to occur is through Saman Dosormi's story of Mak Yong in Bukit Sekam where the artists were supposed to abandon the practice of the art due to the embrace of Sunni Islam among the elite class of the palace. It could be the case that among the changes that took place after the incident was the mask utilization in the performance. If the report by Pudentia (2010) on the arrival Mak Ungu's Mak Yong group in Riau from Pattani 100 years ago was true, perhaps there could be a change of decision in mask utilization within the practice of Mak Yong between the period of Sri Temenggong Village (before World War II) and Mak Ungu's group. This is because, while Mak Ungu's group managed to spread the Masked version of Mak Yong in Riau, its counterpart in Pattani and Kelantan, on the other hand, had abandoned the use of the mask in their performance which ultimately is the inherited version that Malaysia knows today. These possible changes are parallel with the findings from Shafii (2017) that highlights the importance of Tengku Temenggong's patronage where he established Tribunal Diraja that was supposedly to monitor Mak Yong's quality as well as its adherence to Islamic values before his death in 1935. Not only that, he established a payment scheme for the players, his school of arts and culture were also detrimental in the development of Mak Yong's style which is popular in Kelantan today. His status as one of the members from the royal family could potentially lead to prestige bias in adopting Mak Yong cultural traits for the subsequent generations, making the earlier version of utilizing the mask in performance obscure to this day. If we are to take the data from Raman to be the natural cultural transmission of Mak Yong in Kelantan and Riau islands, then the drastic change chosen by the elders of the community could be the reason behind the rift in Mak Yong style before these traits were passed to the next generation. The same could be said to Riau's Mak Yong that no longer use the Rebab in their musical ensemble as shared by Mok Noh who once saw their performance in the Mak Yong's conference organized by SEAMOSPAFA. Further quantitative studies focusing on the pattern of Mak Yong's cultural inheritance is needed to objectively consider Mak Yong's Lamarckian cultural evolution nature.

In preserving cultural heritage, the dual role of Mak Yong and Main Puteri is instrumental in sustaining its cultural influence among the Malay community. As we have gone through the experience of Pattani's Mak Yong community members, Main Puteri does not only serve as a spiritual healing and fulfilment for its members but also acts as an initiation ceremony and has impactful effects on gaining new members of the community. As mentioned by the respondent, most of the time their immediate family does not have any interest in continuing their legacy and the Mak Yong tradition. Main Puteri compliments this in sustaining the community through its cycle of healing-initiating process among the people. With the frequency of Main Puteri shamanistic activities given by the respondent, it can be said that the process of healing-initiation cycle is still going strong in the community and thus its effect and presence is still felt in the region. This healing-initiation process of Main Puteri can be seen as a response to counter against the random nature of cultural drift that would decrease the probability of passing the cultural trait of Mak Yong among the Malay community. Although the intention of the practice in the eyes of the practitioner is by no mean to 'recruit' new members, quite naturally it could be one of the reasons why the culture is still strong in the region. For us to understand the phenomena better in the future, further studies on the distribution of cultural inheritance over several generations among Mak Yong communities in the region could potentially open the door for a better quantitative observation. Using the approach of "power-law distribution" of trait frequencies by Alex Bentley, Matthew Hahn, and Stephen Shennan may provide us with the understanding of the pattern for this quantitative study (2004). Not only could this lead us to the understanding of the cultural drift in Mak Yong community, but it can also act as an indicator of the deviation from the drift model. Such indicator can lead us into the cause of any guided variation influence by the change of policy by the state or the elite class, or any important event that had a deep impact on the community.

While we discuss the role of Main Puteri, one may wonder if Mak Ungu's Mak Yong Group that migrated to Riau also had the ability to perform Main Puteri as well? If this is the case, then perhaps it would be natural if this demic diffusion had also managed to introduce Mak Yong to the Riau community through model-based biased of cultural selection. If we take Riau's Mak Yong cultural transmission as the same as in Raman, then the newly acquainted people of Riau would have preferentially inherited the culture from the respected elders of the Mak Yong community after being spiritually healed through Main Puteri. If this is the case, then this could be one of the reasons why the tradition is still being practice in Riau despite the challenges of modernity against the people of the island. Further investigation is needed on whether or not the culture and traditions are still alive on the island or whether such practice had already diminished 
into non-existent due to cultural drift. If Main Puteri is not being practiced by the people of Riau today, what then would be their respond towards the difficulty of Mak Yong cultural inheritance in the community?

Indeed, interconnected research needs to be done simultaneously in Pattani and Riau island to observe and compare the cultural progression or mutations between these two forms of traditional performing art. While variations between Kelantanese and Raman's Mak Yong is relatively small, the same could not be said to Riau's. If we take the ancestral form of Mak Yong, which utilizes the use of Rebab and Mask, what would be the cause of cultural selection in the dropping of Rebab in Riau and Mask in Kelantan - Pattani? It would be interesting to find the answer on some of these issues including pertaining to the livelihood, the economy, and the social life and inheritance system currently happening in both regions. Our next task is to look at how cultural evolution in Mak Yong affected the different group of Malay communities in the two regions.

Looking into the relationship between Main Puteri and Mak Yong, it could be said that both are interdependent to one another, creating a natural synergy. While both focus on different aspects of the tradition, somehow, they are very similar with some elements overlapping one another. While Mak Yong focuses on the entertainment aspect, Main Puteri, on the other hand, focuses more on the ritualistic and spiritual nature of the tradition. Nevertheless, Mak Yong still has some of its ritualistic element while Main Puteri retains its entertainment aspect in a theatrical dramatic sense during the healing process. Could Mak Yong and Main Puteri both have its common ancestral origin in the past? Among the many traditional performing arts of Pattani - Kelantan, only Main Puteri and Mak Yong seems to share a lot of commonality in its tradition as it is still being practiced inclusively at times with one another. Even within the community itself, some players are able to perform both performances due to its similarity. Could it be the case that both traditions were separated due to the spread of Islam? Was either one of them a part of the other? What are the connections between both of them with Bageh? While we may not certainly determine the answer with these questions, future studies on the inheritance of either culture among the community members could provide us with some enlightenment. One of the possible ways is to utilize phylogenetics research for traditional performing arts that shows similar features in order to determine whether they were descended from the same common ancestral form. As reported by Aboo Backer et al. (2017), the process of healing in Bageh is also similar to Main Puteri despite its main difference of not having orchestral accompaniment. Through breaking the element features of each of these traditional arts, this will enable us to determine on the next necessary steps towards categorizing them through phylogenetics method. Using this method, we could also determine the behaviour of cultural evolution between Mak Yong and other related arts whether they exhibit features of tree-like branch or blending as we compare with other forms of traditional theatre in the region. One of the interesting arguments as pointed out by Alex Mesoudi (2011) is the nature of macroevolution, whether they exhibit treelike or non-treelike structure. The challenge of this path is to determine based on comparison of the cultural evolution between Mak Yong in Riau with Mak Yong, Main Puteri and Bageh in Kelantan - Pattani. Since the arts and culture in Kelantan are often interconnected with one another as the same community of artists is practicing them, blending seems to be an inevitable route at first glance. But what would be the factor behind such instances not to occur? More data is needed at this moment in order for us to determine the answer as we have now reached the limit of this investigation.

As of today, both traditions can be seen as distinct from one another, with Mak Yong catering to the entertaining aspect and the latter for spiritual healing. Evidently, this is also confirmed by Saman, who regards the people of Golok having a strong tradition in Main Puteri and are specialized in it rather than Mak Yong. While both communities of Raman and Golok have the knowledge in Main Puteri and Mak Yong, they are more likely to specialize in one form than the other. It is clear to us that despite some members who are able to perform or participate in either performance, each tradition needs to be approached differently as specific skills and understanding are required to perform them. This could be the reason why some community only focus on one of them even though they are somewhat connected in terms of their social network. The idea is that both seem to share common elements but at the same time is separated. This is an intriguing question that needs to be answered in order for us to understand the cultural evolutionary process surrounding these traditions.

\section{Conclusion}

From the information gained during this preliminary study in Raman, much information has yet to be added in the study of Mak Yong in terms of its social pattern in the community. In this early study conducted in Raman's Mak Yong community, we can observe the synergy between Main Puteri and Mak Yong tradition 
in sustaining its presence in the region despite the decline of Mak Yong as compared to fifty years ago. Thus, this also tells us that to understand the reality of Mak Yong community, one needs to also observe the activities within the network to paint a clearer picture in understanding the past and cultural progress of the Malay community in the region. The approach will also lead us to other forms of traditional performing arts other than Mak Yong as shown in the connection between Mak Yong and Main Puteri. Other than this, other forms such as Menora, Wayang Kulit, Bangsawan, or many others should not be devoid from our discussion in the observation. Despite these intriguing questions and prospects of future studies, this paper only acts as a preliminary step to understand the nature of Mak Yong in Raman while at the same time compare some of its elements with Mak Yong in other parts of the Malay world through Darwinian Cultural Evolution epistemological view. Although having Raman Mak Yong community as a primary source of the study, we should not alienate the community from the rest of its rich history including connections to other types of Mak Yong in Kelantan and Riau. The reality is that, despite sharing similar conventions and history in the past, our next task at hand is to determine the process that had occurred leading to its current state and affairs today. While each regional type can be studied separately, only through connecting these different types of regional Mak Yong's can we understand the social and cultural phenomena that had occurred, leading to its current unique interpretations of the same tradition shared in the past. Ultimately, it is in hope that through this study we are able to understand the cultural evolution of the Malay culture in the region.

\section{Notes}

All interviews for this paper were conducted between $11^{\text {th }}$ to $12^{\text {th }}$ of September 2019 in several locations around Raman District, Yala Province of Thailand; in Ban Kue Meng and Ban Ba Ngo Yue Baeng. Participants from these interviews include Saman Dosormi, Minoh Saman (Mok Noh), Lateh Senik (Che Teh), Nawar Samat/ Selamoh (Mok Moh), Dain Senik (Che Din), Timoh Senik (Mok Timoh) and Dahari Emong (Wori).

\section{References}

Abdullah, S. M. (2019, September 26). Kelantan lifts ban on Mak Yong. New Straits Times, 9.

Aboo Backer, M. B., Manoharan, P. \& Shafii, A. S. H. (2017). The mind, body, spirits, and soul in traditional healing: A perspective of Bageh. In Shafii, A. S. H., Abdullah, N. F. L. \& Aboo Backer, M. B. (Eds.). locating the soul of healing performance in Malaysia. (pp 24-33). Penerbit Universiti Sains Malaysia.

Bentley, R. A., Hahn, M. W., \& Shennan, S. J. (2004). Random drift and culture change. Proceedings of the Royal Society: Biological Sciences, 271(1547), 1443-1450. https://doi.org/10.1098/rspb.2004.2746

Cuisinier, J., (1936). Danses magiques de Kelantan. Institut D'Ethnologie.

Hardwick, P. A. (2009). Stories of the wind: The role of shamanistic healing in Kelantan, Malaysia (Publication No. 3386680) [Doctoral dissertation, Indiana University]. ProQuest Dissertations Publishing.

Mesoudi, A. (2011). Cultural Evolution: How Darwinian theory can explain human culture and synthesize the social sciences. The University of Chicago Press.

Mohamad, Z. (2012). Report: The Mak Yong spiritual dance heritage conference, performances, and workshops. Asian Theatre Journal, 29(2), 445-460. https://doi.org/10.1353/atj.2012.0050

Nasuruddin, M. G. (1995). The Malay dance. Dewan Bahasa dan Pustaka.

Phongphaiboon, S., Thanasuk, S. \& Kawhkhao, P. (2000). Knocking rust off the dagger: A look at the way of life of the people of the lower south. The Thailand Research Fund.

Pudentia, MPSS. (2010). The revitalization of Mak Yong in the Malay world. Wacana, Journal of the Humanities of Indonesia, 12(1), 1-19.

Shafii, A. S. H. (2017). Management style of Kelantan Mak Yong. In Nasuruddin, M. G. (Ed. \& Trans.). Mak Yong - Malaysian legacy world heritage. (pp. 271-291). The Department of National Heritage, Malaysia.

Shafii, A. S. H., Ishak, S. \& Abdullah, N. F. L. (2017). The mystical gathering between the supernatural, physical and the nether world of Main Teri among the Malay Community. In Shafii, A. S. H., Abdullah, N. F. L. \& Aboo Backer, M. B. (Eds.). Locating the soul of healing performance in Malaysia. (pp. 34-41). Penerbit Universiti Sains Malaysia.

Sheppard, M. (1974). Ma'Yong: The Malay dance drama. In Osman, M. T., (Ed.). Traditional drama and music of Southeast Asia (pp. 133-142). Dewan Bahasa dan Pustaka.

Sheppard, M. (1972). Taman indera: Malay decorative arts and pastimes. Oxford University Press.

Skeat, W. W. (1900). Malay magic. The Macmillan Company.

Yousof, G-S. (2014). Issues in traditional Malay culture. Patridge Publishing. 
Yousof, G-S. (2004). Panggung inu: Essays on traditional Malay theatre. UniPress, The Centre for the Arts, National University of Singapore.

Yousof, G-S. (1992). Panggung semar: Aspects of Malay theatre. Tempo Publishing.

Yousof, G-S. (1976). The Kelantan Mak Yong dance theatre: A study of performance structure [Doctoral dissertation, University of Hawaii]. http://hdl.handle.net/10125/12168 